Acta Hispanica (2019) 24: 9-17

\title{
COMENTÁRIOS SOBRE O ESTATUTO INDEPENDENTE DE ALGUNS PREFIXOS PORTUGUESES
}

\author{
ÁGNES BAKó \\ Universidade Eötvös Loránd, Budapeste
}

\begin{abstract}
Resumo: O objetivo deste trabalho é apresentar uma característica pouco conhecida e atípica dos prefixos portugueses, que é o seu possível estatuto independente na frase. Só consideramos os prefixos que participam hoje na derivação das palavras vernáculas portuguesas. Portanto analisamos os prefixos des-, in-, super-, sobre-, sub-, pré-, pós- e re-, tirando os exemplos derivados com estes prefixos do corpus Cetempúblico. Esta característica atípica dos prefixos está relacionada com a sua função atributiva e substantival, porque neste sentido podem ser considerados elementos com estatuto independente.
\end{abstract}

Palavras-chave: português, prefixos, estatuto independente, corpus

Abstract: The aim of this work is to represent the less known and atypical characteristic of Portuguese prefixes which is their possible independent status in the sentence. Prefixes that participate actively in the derivation of Portuguese words: des-, in-, super-, sobre-, sub-, pré-, pós- and re- will be analysed. The examples created with the above mentioned prefixes are taken from Cetempúblico corpus. The rare characteristic of prefixes is related with their attributive and substantival function because in this sense they can be considered as items with independent status.

Keywords: Portuguese, Prefixes, Independent Status, Corpus

\section{Introdução}

Neste artigo tencionamos destacar algumas características atípicas dos prefixos portugueses, isto é, vamos examinar o seu possível estatuto independente numa frase. Primeiro, faremos uma lista que tem exclusivamente aqueles elementos de formação que são unanimemente considerados prefixos nos diferentes estudos e gramáticas (Ching, 1971-1973; Cunha - Cintra, 1984; Vilela, 1994; Villalva, 2003).

Tendo restringido a área de investigação, analisaremos as características fonológicas, morfológicas e morfossintáticas prefixais. A análise vai-se basear nos exemplos obtidos do corpus online acessível, Cetempúblico (Santos - Rocha, 2001, 11-05-2018). Depois dos exemplos indicar-se-á a referência com o início do código CP. 
Comentários sobre o estatuto independente de alguns prefixos portugueses

\section{Os prefixos analisados}

Como define Villalva (2003:942), os prefixos ocorrem à esquerda da forma de base, não interferem na categoria sintática da palavra em que aparecem. Além disso, não determinam o valor das categorias morfológicas, morfossintáticas e morfossemânticas, mas podem coocorrer em posições adjacentes (Villalva, 2003:942).

Pelo facto de existir muitos tipos de elementos de formação que podem figurar perante uma base, entre eles pode-se distinguir diferentes tipos, por exemplo prefixos, pseudoprefixos ou radicais eruditos. Daí a discordância no que diz respeito ao agrupamento de elementos, sendo bastante problemático traçar uma fronteira clara entre eles.

Por conseguinte, nas diversas obras linguísticas pode-se ver uma vasta variedade dos agrupamentos. Os seguintes prefixos são listados por Ching (1971-1973:127-212): anti-, contra-, não-, in-, a-, des-, ex-, super-, supra-, sobre-, ultra-, extra-, biper-, arqui-, sur-, sub-, infra-, bipo-, vice-, trans-, inter-, intra-, semi-, meio-, para-, quase-, pré-, pós-, recém-, uni-, bi-, tri-, quadri-, multi-, pluri-, poli-, pró-, co-, re-, auto-, pan-, neo- e pseudo-. Comparando a lista de Ching com a de Vilela, no capítulo de Vilela (1994:183) aparece quase o mesmo agrupamento com a exceção dos seguintes elementos: sur-, uni-, bi-, tri-, quadri-, multi-, pluri-, poli-, pan- e pseudo-. Ao mesmo tempo, ele enumera outros que já não podem ser considerados produtivos, por exemplo epi-, ecto-, exo-, etc (Vilela, 1994:183). Cunha - Cintra enumeram (1984:87-89) os prefixos segundo a sua origem latina ou grega, assim a sua lista difere bastante das anteriormente analisadas porque aparecem nela muitos prefixos com que já não criam produtivamente palavras vernáculas, por exemplo aná-, per-, etc. Finalmente, afirma Villalva (2003:965) que no português são bastante poucos os prefixos que têm maior grau de intervenção, limitando a lista dos mais frequentes a: des-, in-, re-, super-, prée pós-.

Por conseguinte, para a análise escolhemos os elementos comuns das diferentes listas que consideram prefixos. Omitimos os elementos que podem aparecer também à direita da palavra, os elementos que têm um significado mais concreto do que um simples prefixo -por exemplo o significado de helio- pode-se esclarecer como o elemento designativo de Sol ao contrário de um prefixo que dependentemente da sua base pode ter mais significados (por exemplo, sobre- pode ter significado locativo e superlativo) - e os elementos com os quais já não criam palavras vernáculas. Deste modo excluímos os pseudoprefixos, radicais eruditos e prefixos improdutivos. Pode-se concluir a partir das obras escritas por Ching, Vilela, Cunha - Cintra e Villalva, que in-, des-, super-, sobre-, sub-, pré-, pós- e re- são tratados unanimemente como prefixos. Assim temos a lista dos prefixos para analisar. 
Ágnes Bakó

Quanto à metodologia da análise, procuramos as ocorrências e os exemplos especiais destes prefixos e depois tentamos encontrar traços comuns entre eles. Sintetizando as características em comum, mostramos a sua correlação com o possível estatuto independente dos prefixos. A análise deste artigo vai tratar das características destes elementos de ponto de vista fonológico, morfológico e morfossintático, observando as suas ocorrências nos diferentes contextos no corpus Cetempúblico (Santos - Rocha, 2001).

O resultado da análise vai ser resumido na tabela da conclusão de que se revelará que estas características se relacionam com o possível estatuto independente de certos prefixos.

\section{Características dos prefixos}

\subsection{In- e des-}

Ambos os prefixos pertencem aos prefixos de negação. Des- refere-se à separação e à privação, enquanto in- e os seus alomorfes $(i-, i r$-, im- $)$ significam negação ou privação (Cunha - Cintra, 1984:87). Os dois prefixos têm as características dos prefixos prototípicos, isto é, são átonos, não alteram a categoria gramatical da base, bem como conservam os traços morfossintáticos da base (Sziij), 2009:182).

Estes prefixos podem aparecer combinados com outros prefixos, até mesmo com outro prefixo de negação na mesma palavra. Quando des- e in- aparecem juntos numa palavra, às vezes causam redundância, por exemplo no caso de infelize desinfeliz. (Sziij, 2010:12).

Quanto à recursividade deles, no corpus Cetempúblico não se encontra exemplos para a utilização recursiva de des- e de in-. Não podem aparecer independentemente numa frase, já que não têm função preposicional, atributiva ou substantival. O prefixo despode ocorrer sem que modifique o significado da palavra, por exemplo alvorar e desalvorar significam o mesmo.

\subsection{Super- e sobre-}

Super- e sobre- têm a mesma origem etimológica, ficam no mesmo grupo por razões semânticas, já que originariamente ambos expressaram significado ligado à posição, por exemplo sobrepor CP 6306-soc-93a-1, supervisionar CP3326-pol-94b-1. Posteriormente obtiveram outro significado, funcionando assim além de prefixos posicionais, também como prefixos de intensidade (sobrevalorizar CP75353-nd-93b-1, super-feliz CP63706-des97a-2), portanto super- e sobre- servem para exprimir posição superior e excesso (Cunha 
Comentários sobre o estatuto independente de alguns prefixos portugueses

- Cintra, 1984:89). Contrariamente às características típicas dos prefixos, os prefixos super-e sobre- são tónicos (Villalva, 2003:964).

Passando às questões morfológicas, pode-se concluir com base nos exemplos de Cetempúblico que há várias possibilidades de reforçar ainda mais o sentido intensivo da palavra prefixada. É um fenómeno frequente que um sufixo aumentativo se acrescenta à palavra prefixada, por exemplo super-chavão (CP194821-nd-95b-2). O aspeto da recursividade também está conectado com a intensificação do significado da palavra, por exemplo super-supercomputador (CP555850-com-98a-3). Por último, além da duplicação do mesmo prefixo, existem casos em que super- se combina com outro prefixo, por exemplo super-hiper-famoso (CP458006-des-91a-2).

Para sublinhar o carácter independente deste prefixo, mostramos em que contextos é possível a sua utilização com função substantival e adjetival. Como substantivo significa um tipo de gasóleo (1):

(1) “A extinção da «super» nessa data não deverá representar um grande problema para estes carros" (CP117967-nd-98a-1).

O elemento super pode funcionar independentemente como adjetivo também (2 e 3). Com o estatuto adjetival refere-se a uma coisa muito boa (2). Do exemplo (3) pode-se concluir que não se acrescenta ao adjetivo a marca $-s$ do plural:

(2) "De «super» nada tem e, em termos objectivos, pode resumir-se em dois adjectivos: modesto e competente" (CP149844-clt-94b-1).

(3) "Mas claro, os jogos da Bundesliga são normais, estes são super, têm outra motivação" (CP148475-des-93b-1).

O prefixo sobre- não é tão popular como super- (Ching, 1971-1973:146). Estes prefixos estão frequentemente em alternância, em detrimento da utilização de sobre-, o que causa que o prefixo sobre- tenha começado a perder o seu sentido superlativo (HonrubiaNúñez, 2011:313). Esta é uma tendência observada no espanhol, mas inferindo do número e da proporção de palavras vernáculas portuguesas prefixadas com super- e sobre-, podemos ver que a afirmação também é válida para o português. Da tabela na conclusão pode-se ver que o prefixo sobre- não pode desempenhar nem a função de substantivo, nem a função de adjetivo. Contudo, funcionando como preposição pode ser palavra independente numa frase.

\subsection{Sub-}

Ching (1971-1973:157) considera o prefixo sub- como um prefixo que expressa desvalorização (suborçamentação CP527308-clt-98b-2) e subordinação (sub-prefeitura CP1070395-soc-93b-1), além do seu significado locativo (submaxilar CP349795-clt-soc- 
Ágnes Bakó

95a-2). Segundo Ching (1971-1973:158) dentro deste grupo sub- é o prefixo mais frequentemente utilizado. A análise dos exemplos do Cetempúblico dá o mesmo resultado.

O prefixo sub- pode ocorrer com função atributiva (4), bem como pode ter função substantival, como vemos nos seguintes exemplos $(5,6)$ :

(4) 'Depois, nos dias 27, 28 e 29 de Dezembro, a selecção de sub 22 deslocar-se-á ao Luxemburgo para participar num torneio quadrangular, frente à Checoslováquia, Suíça e Luxemburgo" (CP312829-des-91b-1).

(5) “A «sub» demitiu-se" (CP578523-pol-95b-2).

(6) "Mas é no «sub» que reside a soberania" (CP83130-clt-95a-2).

Apesar de existir a sua forma preposicional concorrente sob, por vezes sub- também é utilizado aparentemente como preposição que depois funciona como atributo num sintagma nominal, por exemplo (4) seleç̧ão de sub 22.

Quanto à sua recursividade, sub- pode ser usado em posição adjacente com base nos exemplos seguintes: sub-sub-clã (CP154555-pol-98a-1), sub-sub-subaproveitados (CP626482pol-92b-1) e sub-sub-subsídio (CP292250-soc-95a-1). Pode-se também combinar com outros prefixos: subdesemprego (CP95414-opi-97a-2), sub-pós-neo-culturas (CP231046-clt$93 \mathrm{~b}-1)$, etc.

\subsection{Pré- e pós-}

Os prefixos pré- e pós- expressam exclusivamente sentido posicional, quer temporal, quer locativo, pré- exprime anterioridade (pré-adolescência CP770942-nd-94b-2) e pósrefere-se à posterioridade (pós-acidente CP311945-nd-92a-1).

Uma outra característica comum é que o prefixo pré-, bem como o prefixo pós- são prefixos tónicos. Pode-se utilizar ambos os prefixos de modo recursivo, como os seguintes exemplos mostram: pré-pré-cenário (CP168855-pol-96b-4), pré-pré-campanha (CP124160-nd-95b-1), pré-pré-candidato (CP474158-clt-94a-1), pré-pré-candidatura (CP1248735-nd-96a-2) e pós-pós-guerra (CP120017-nd-95b-4), pós-pós-indústria (CP85713clt-96a-1); pós-pós-moderno (CP1347373-clt-92a-3).

Além da sua ocorrência adjacente, é frequente a combinação com outro prefixo, quer com um elemento antónimo (pré-pós-modernista CP505233-clt-95b-1), quer com outro tipo de elementos (pré-neo-clássico (CP162459-clt-94a-1).

Ambos prefixos têm estatuto independente mas divergem no tipo da sua função independente. Por um lado, pré- pode ter função atributiva (7) e preposicional (8): 
Comentários sobre o estatuto independente de alguns prefixos portugueses

(7) "Noticiários de televisão que nesta fase «pré» ainda tentam não ser descaradamente propagandísticos" (CP142675-pol-94b-3).

(8) "Emergiram em 1987, regredindo à música rural pré ou paralela ao advento do rock'n 'roll, neotradicionalismo que combinaram com uma visão socializante e independentista, expressa nas letras e na acentuação da sua pronúncia escocesa" (CP1149458-clt-94a-1).

Por sua vez, pós- pode desempenhar função substantival $(9,10)$ :

(9) “Ao «pós» sucedeu o «trans»..." (CP57138-clt-93a-1).

(10) “Elas é que são modernas, com ou sem «pós»” (CP253352-nd-94b-2).

\section{5. $R e-$}

Re- é o prefixo que na maioria das vezes expressa repetição e ação retroativa de um estado passado (Ching, 1971-1973:202). Com base nos exemplos encontrados no corpus Cetempúblico (Santos - Rocha, 2001) não pode desempenhar nem função atributiva, nem substantival, ou seja, este prefixo não tem estatuto independente.

A utilização deste prefixo de maneira recursiva é possível, como podemos observar na palavra seguinte: re-rebobinar (CP682873-nd-94b-2). A combinação dele com outros prefixos é um fenómeno mais frequente do que a recursividade de re-: redescolar (CP64314-soc-93a-2), reenraizamento (CP439586-clt-93b-1), recontextualizar (CP54255-clt95a-1), etc.

O prefixo re- pertence aos prefixos átonos, como mostra a seguinte transcrição fonética da palavra recortar, em que a vogal $e$ fica reduzida numa sílaba átona: [Rəkur' tar].

O prefixo re-pode ser considerado um prefixo especial uma vez que com ele podem formar-se palavras sem aparecer o seu significado ligado à repetição e ação retroativa de um estado passado, por exemplo recôncavo (CP394873-nd-93a-2).

\section{Conclusão}

Finalmente resumimos o resultado da análise na seguinte tabela. $\mathrm{Na}$ tabela pode-se ver as características de cada prefixo. Marcamos com + se o prefixo respetivo tem a característica ou desempenha a função, e indicamos com - se não. Com ? mostramos os casos que não são evidentes. As colunas $N$ "nome", $A$ "adjetivo" e $V$ "verbo" mostram a que categoria gramatical se pode adicionar o prefixo. Só sublinhamos os casos especiais a que Ching -que escreveu uma publicação abrangente sobre os prefixos portugueses (Ching, 1971-1973) - não prestou atenção ou o seu corpus não conteve tais exemplos. Analisamos a relação entre a tonicidade, a recursividade e as categorias 
gramaticais às quais os prefixos se adicionam, para mostrarmos como relacionam estas características com o estatuto independente dos prefixos.

\begin{tabular}{|c|c|c|c|c|c|c|c|c|}
\hline & $\mathrm{N}$ & $\mathrm{A}$ & $\mathrm{V}$ & $\begin{array}{c}\text { Função } \\
\text { atributiva }\end{array}$ & $\begin{array}{c}\text { Função } \\
\text { substantival }\end{array}$ & $\begin{array}{l}\text { Característica } \\
\text { recursiva }\end{array}$ & $\begin{array}{c}\text { Possibilidade } \\
\text { da } \\
\text { combinação } \\
\text { com um } \\
\text { outro } \\
\text { prefixo }\end{array}$ & Tonicidade \\
\hline $\begin{array}{l}\text { in } \\
\text { des }\end{array}$ & $\begin{array}{l}+ \\
+ \\
+\end{array}$ & $\begin{array}{l}+ \\
+ \\
+\end{array}$ & $\begin{array}{l}+ \\
+ \\
+\end{array}$ & - & - & $\begin{array}{l}- \\
-\end{array}$ & $\begin{array}{l}+ \\
+\end{array}$ & $\begin{array}{l}?+ \\
-\end{array}$ \\
\hline $\begin{array}{l}\text { super } \\
\text { sobre }\end{array}$ & $\begin{array}{l}+ \\
+\end{array}$ & $\begin{array}{l}+ \\
+\end{array}$ & $\begin{array}{l}+ \\
+\end{array}$ & $\begin{array}{l}+ \\
-\end{array}$ & $\begin{array}{l}+ \\
-\end{array}$ & $\begin{array}{l}+ \\
-\end{array}$ & $\begin{array}{l}+ \\
+\end{array}$ & $\begin{array}{l}+ \\
+\end{array}$ \\
\hline sub & + & + & + & + & + & + & + & $?$ \\
\hline $\begin{array}{l}\text { pré } \\
\text { pós }\end{array}$ & $\begin{array}{l}+ \\
+ \\
+\end{array}$ & $\begin{array}{l}+ \\
+\end{array}$ & $\begin{array}{l}+ \\
+ \\
+\end{array}$ & $\begin{array}{l}++ \\
-\end{array}$ & $\begin{array}{l}\overline{-} \\
+\end{array}$ & $\begin{array}{l}++ \\
+\end{array}$ & $\begin{array}{l}+ \\
+\end{array}$ & $\begin{array}{l}+ \\
+\end{array}$ \\
\hline re & + & + & + & - & - & + & + & - \\
\hline
\end{tabular}

Características sintáticas, morfológicas e fonológicas dos prefixos analisados

Para concluir a análise, poder-se-ia afirmar que todos os prefixos da tabela se podem acrescentar a uma base substantival, adjetival e verbal. Apesar disso, des- primeiro associa-se a bases adjetivais ou verbais, enquanto in-tipicamente a bases adjetivais e religa-se a bases verbais. Segundo a afirmação de Villalva (2003:964) unicamente no caso dos prefixos átonos é possível detectar uma derivação subsequente à derivação. No que diz respeito à derivação subsequente à derivação, podemos ver que em muitos casos falta o equivalente nominal, adjetival ou verbal da palavra prefixada. Como afirma Pena (2011:219) em espanhol também se encontra lacunas nas séries derivacionais formadas pela prefixação, por exemplo o equivalente espanhol do verbo latino perficere não existe, em vez disso criaram o verbo perfeccionar com base no nome perfección. Quanto à forma e à conjugação dos verbos prefixados, podemos encontrar irregularidades. Alguns verbos com prefixos mostram a mesma irregularidade que o verbo simples, p. ex. desfazer: desfaço, desfiz etc., ao passo que em outros paradigmas acontece a regularização, p. ex. requerer-requeri em vez de requerer-*requis (Szijj, 2014:474).

Sobre as funções desempenhadas, podemos concluir que super- e sub- podem ter função atributiva e substantival. O elemento pré- tem função atributiva, ao passo que pósdesempenha um papel substantival. O prefixo sobre- pode aparecer como preposição, bem como o prefixo pré-. 
Todos os prefixos analisados podem ser combinados com outros prefixos também. É um traço comum.

Quanto à recursividade, apenas in-, des- e sobre-são aqueles dos prefixos analisados que não podem ser utilizados de modo recursivo. Os prefixos tónicos super-, sobre-, pré-, póse sub- podem aparecer de modo recursivo numa palavra. O prefixo re- também pode ser utilizado recursivamente mas apenas isto não causa que tenha estatuto independente numa frase.

Super-, sobre-, pré- e pós- são tónicos porque a sua vogal não fica reduzida. No caso de sub- e in- não se pode determinar facilmente o carácter tónico ou átono, pois estas vogais não ficam reduzidas na posição átona. Des- e re- evidentemente são átonos por a vogal $e$ - ficar reduzida na palavra.

Pode ver-se que in-, des- e re-são átonos e -exceto re-- não podem ser recursivos. Estes não podem ocorrer com estatuto independente numa frase. A impossibilidade de ficar independentemente numa frase provavelmente se relaciona com a falta da tonicidade, a da recursividade e a ocorrência deles numa palavra em que não têm qualquer função semântica, por exemplo rebaixa (CP560392-soc-96a-2), recensear (CP314-pol-92b-2).

Concluindo, entre os prefixos produtivos portugueses destacam-se super-, sobre-, sub-, pré- e pós-, no que diz respeito à posição independente na frase.

\section{Referências bibliográficas}

Ching, Li (1971-1973). Sobre a formação de palavras com prefixos em português actual. Boletim de Filologia, XXII. 197-234.

Cifuentes Honrubia, José Luis - Fresnillo Núñez, Javier (2011). From Latin super- to Spanish sobre- (Aspects on semantic evolution in verb formation). In: Cifuentes Honrubia, José Luis - Rodríguez Rosique, Susana (eds.). 2011. Spanish Word Formation and Lexical Creation. Amsterdam/Philadelphia: John Benjamins Publishing Company. 307-345.

Cunha, Celso - Lindley Cintra, Luís (1984). Nova Gramática do Português Contemporâneo. Lisboa: Edições João Sá da Costa.

Pena, Jesús (2011). The relationship between verb-noun in derivational series. In: Cifuentes Honrubia, José Luis - Rodríguez Rosique, Susana (eds.). 2011. Spanish Word Formation and Lexical Creation. Amsterdam/Philadelphia: John Benjamins Publishing Company. 217-231.

Santos - Rocha (2001). www.linguateca.pt, fecha de consulta: 11-05-2018. 
Ágnes Bakó

Szijj, Ildikó (2014). Verbos irregulares com prefixo em português e outras línguas românicas. In: Rzepka, Anna - Czopek, Natalia (eds.). 2014. Studia Iberystyczne. Universos de língua portuguesa em debate. Cracóvia: Ksiegarnia Akademicka. 473-486.

Szijj, Ildikó (2010). Os prefixos in e des em português. In: Pál, Ferenc - Urbán, Bálint (eds.). 2010. Actas do congresso organizado por motivo dos trinta anos do português na Faculdade de Letras da Universidade Eötvös Loránd de Budapeste (CD). Budapest: Departamento de Língua e Literatura Portuguesas da Faculdade de Letras da Universidade Eötvös Loránd de Budapeste. 1-12.

Sziji, Ildikó (2009). Prefixos que expressam anterioridade em português. Études Romanes de Brno, 30. 181-188.

Vilela, Mário (1994). Portugiesisch: Wortbildungslehre. In: Holtus, Günter - Metzeltin, Michael - Schmitt, Christian (eds.). 1994. Lexikon der Romanistischen Linguistik. vol. VI. 2. Tübingen: Max Niemeyer Verlag. 173-199.

Villalva, Alina (2003). Formação de palavras: afixação. In: Mateus, Maria Helena Mira Brito, Ana Maria - Duarte, Inês - Faria, Isabel Hub. 2003. Gramática da Lingua Portuguesa. Lisboa: Editorial Caminho. 2003. 939-965. 